\title{
Investigation of Vegetative Properties and Generative Production of the Potential Ornamental and Narrow Endemic Species Verbascum yurtkuranianum (Scrophulariaceae) for Ex situ Conservation
}

\author{
Kamil Erken *
}

\begin{abstract}
Verbascum yurtkuranianum is a narrow endemic species occurring in a single location, the northern Bursa province (Turkey). It is an endangered and potentially ornamental plant. No conducted study on its life and biology, production, and aesthetic features is available. This study aimed to reveal its vegetative properties, seed characteristics, methods and requirements for seed germination, germination speed, and potential ornamental value so it can be conserved ex situ and produced. Verbascum yurtkuranianum has potential value as an ornamental plant regarding its aesthetic features as a flower. This study revealed that the total number of individuals in the species is 788 . Without any treatment, $70.7 \%$ germination rate is achieved if the seeds are stored at $4{ }^{\circ} \mathrm{C}$. The optimum germination temperature was from 15 to $20{ }^{\circ} \mathrm{C}(77.3 \%$ and $78.7 \%$, respectively), and the photoperiod regulation for seed germination was $12 / 12$ or $8 / 16$ (light/dark) hours ( $74.7 \%$ and $76.0 \%$, respectively). The most effective treatment to promote germination rate was found by implementation of 60 min ultrasonic waves $(94.3 \%)$ or application of 120 min vacuum (95.3\%). Germination occurred between 8 and 10 days. A parcel of ex situ conservation was constituted with the seedlings obtained from the germination studies.
\end{abstract}

Keywords: Verbascum yurtkuranianum; Endemic; Ex situ conservation; Seed germination; Ultrasonic wave; Vacuum; Ornamental plant

Contact information: Bursa Technical University, Faculty of Forestry, Landscape Architecture Department, 16310, Bursa,Turkey; *Corresponding author: kamil.erken@btu.edu.tr

\section{INTRODUCTION}

Today, the growing threats to biodiversity and ecosystems and the decline of certain species to the degree of extinction are considered the most severe problems of our time (K1rmizi et al. 2019). One of the primary conditions for conservation and sustainable use of biodiversity is securing endangered species and enhancing the protection endeavors to preserve remaining ecosystem fragments (Ganatsas et al. 2019; Locke et al. 2019). Pursuant to international agreements, protection of endemic and rare species is a requirement. Each signatory country of the Rio Convention is required to take their biological inventories and the necessary measures to conserve them (Ocak et al. 2017). In spite of these measures, endemic plants cannot be conserved sufficiently, and they are left endangered (Öztürk and Yiğit 2013). One of the ways to minimize the impacts of these dangers is being aware of the germination and dormancy behaviors of endemic species and conserving them accordingly in situ and ex situ (K1rmiz1 et al. 2019).

In situ and ex situ conservation of endemic and rare species requires comprehension of knowledge about the habitat and life biology of the plant (Ganatsas et al. 2019). This 
information constitutes critical subjects for conservation and sustainable use. To protect and reproduce endangered and endemic species, revealing the seed germination characteristics is one of the primary issues (García et al. 2012; Schnadelbach et al. 2016; Ganatsas et al. 2019). The knowledge of the germination period and the plant production rate heavily influences the fertility of production works. Therefore, it is critical to carry out the works for reproduction by being conversant with the germination tendencies of the plant (Cesur et al. 2017).

In this day and age, reducing the use, care costs, and water consumption of native species of a locality in ecological landscape design is considered to be the most important factor of sustainability, and this approach is becoming increasingly widespread (Brzuszek et al. 2010; Çetin and Mansuroğlu 2019). Making native species usable for commercial purposes requires successive long-term studies (Pollock and Biante 1996). The early stages of the study identify the characteristics of the species or genotype and determine the germination features (Mikkelsen 1987; Henting 1998).

The V. yurtkuranianum taxon, introduced to the scientific community in 2006, is a global endemic plant surviving with 788 individuals in a single locality. It exists in small groups in a $2 \mathrm{~km}^{2}$ area (Kaynak et al. 2006). Because these spots are high-risk highway drainage channels, picnic sites, and natural gas pipeline routes precariously close to countryside dwellings, the risk level of being critically endangered (CR) according to IUCN criteria is extremely high (Çenil 2007; Erdoğan et al. 2011). The species is likely to lose more than $50 \%$ of its individuals in the next 10 years. Therefore, this species, which has potential for becoming an ornamental plant (due to its bright green, glabrous basal leaves, purple-violet corollas, and long flower life) is under immense pressure.

Many plant species manifest dormancy for different reasons and suspend germination until ready to grow seedlings (Baskin and Baskin 2014). Stratification and certain chemical treatments are known to terminate dormancy and enhance germination rates for seeds (El-Dengawy 2005; Jones et al. 2016; Peng et al. 2017). Except for using chemical substances, other practices are available for inserting water into the seed via vacuum or pressure to promote germination (Miyoshi and Mii 1998; Custódio et al. 2016; Katsalirou et al. 2019). Another treatment that began to be used to terminate dormancy in seeds and enhance germination percentage is ultrasonic wave implementation (Luo 2016; Nazari and Eteghadipour 2017; Wong et al. 2019).

Reproducing endemic and potential ornamental taxa by establishing the production methods - that benefit from them as ornamental plants on the condition that they are ex situ conserved and their sustainability is ensured - will provide multiple advantages regarding both the protection of biodiversity and transformation of natural resources into economic values. There are studies on the morphological characteristics of $V$. yurtkuranianum as one of these species (Kaynak et al. 2006; Çenil 2007; Erdoğan et al. 2011). However, no study of its ornamental plant features and ex situ conservation is available. This study aimed to establish the most ideal generative production methods for the global endemic species $V$. yurtkuranianum in a laboratory setting, to find a resource garden with the reproduced plants using the established methods for $e x$ situ conservation, promotion, and cultivation works, and to determine the extent of the landscape value for the species. 


\section{EXPERIMENTAL}

\section{Materials}

Verbascum yurtkuranianum seeds used in the study were collected from Ericek village $\left(40^{\circ} 19^{\prime} 06^{\prime \prime} \mathrm{N}, 2^{\circ} 15^{\prime} 52^{\prime \prime} \mathrm{E}\right)$ of Bursa, Turkey $\left(40^{\circ} 11^{\prime} 40^{\prime \prime} \mathrm{N}, 2^{\circ} 03^{\prime} 14^{\prime \prime} \mathrm{E}\right)$ (Fig. 1). There were three locations where the seeds were collected: location $1\left(40^{\circ} 18^{\prime} 56^{\prime \prime} \mathrm{N}\right.$ $29^{\circ} 15^{\prime} 32^{\prime \prime}$ E, $\left.681 \mathrm{~m}\right)$, location $2\left(40^{\circ} 18^{\prime} 56^{\prime \prime} \mathrm{N}, 2^{\circ} 16^{\prime} 22 \mathrm{E}, 704 \mathrm{~m}\right)$, and location 3 $\left(40^{\circ} 18233^{\prime \prime} \mathrm{N}, 2^{\circ} 17^{\prime} 25^{\prime \prime} \mathrm{E}, 739 \mathrm{~m}\right)$. Morphological measurements and physiological observations were made in three groups of the plants selected from these locations.

Seeds were collected on 24 July 2019 and 29 July 2020. They were put in a $4{ }^{\circ} \mathrm{C}$ freezer on September $1^{\text {st }}$. They were kept in the cold freezer until the experiments were conducted. In 2020 , some seeds were put into room conditions $\left(20^{\circ} \mathrm{C}, 50 \% \mathrm{RH}\right)$, for seed storage temperature tests.

\section{Methods}

Determining the ornamental plant potential, morphological and physiological features

The locality of the population was periodically visited between April and August to observe physiological and aesthetic features of the plant. Morphological, physiological, and life-biology-related observations and measurements were performed. This data also ascertains whether the species has potential ornamental plant value and provides insight regarding the aesthetic and functional characteristics of the plant for landscape use (Alp et al. 2020; Erken et al. 2021). Measurements were made in 2020 on 20 plants randomly selected from each population at three different locations (Fig 1.).

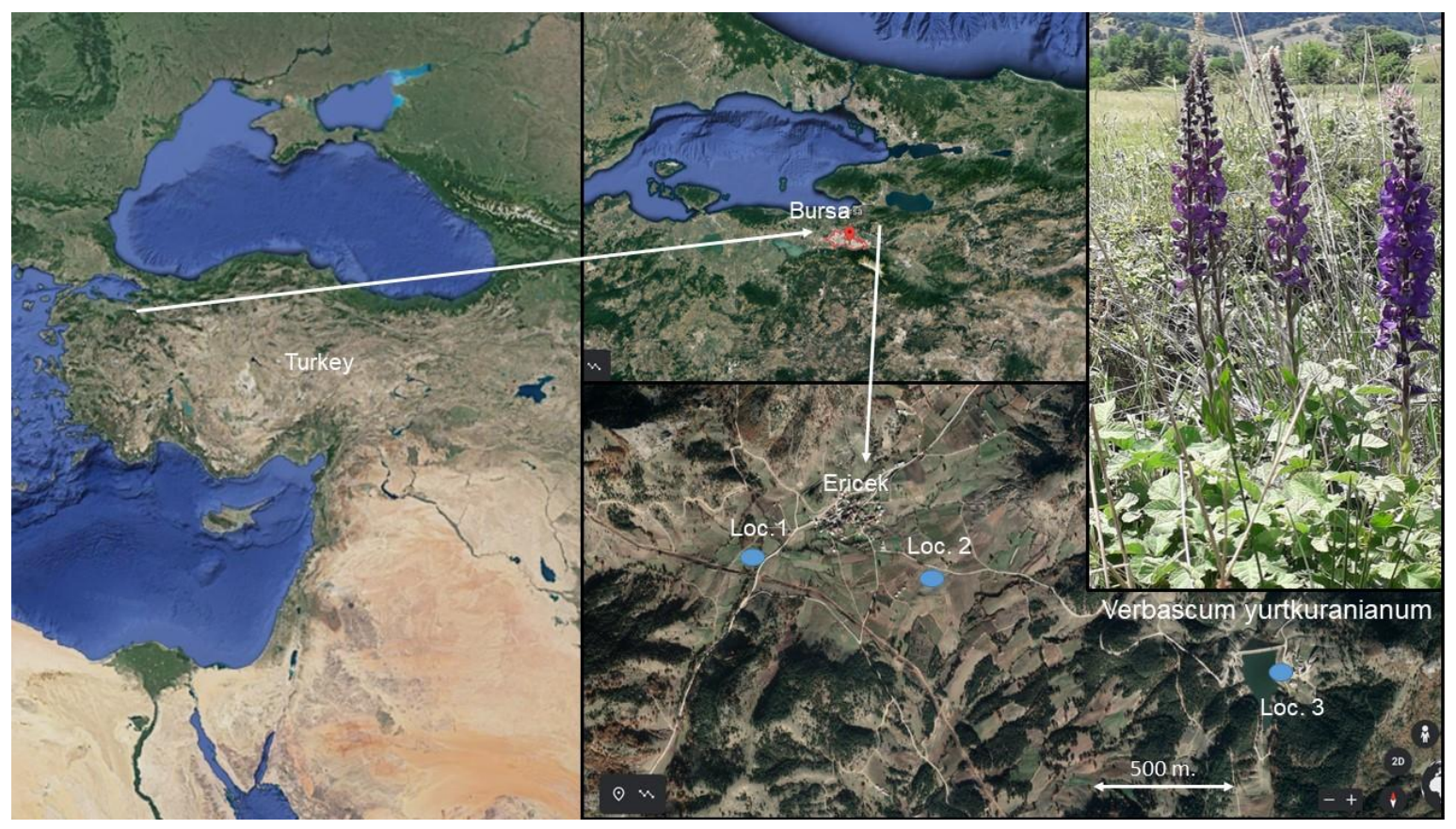

Fig. 1. Images indicating the locations of the $V$. yurtkuranianum where the plants were measured and the seeds were collected 
Because the species is endemic and insufficient in the number of individuals, seeds were randomly collected in limited numbers to not damage the population pursuant to the protocol stated in Bacchetta et al. (2006). After collection, the seeds were air-dried in room conditions for 7 days. Twenty-five seed capsules were randomly selected to reveal the average seed count in a capsule, and the number of seeds considered healthy, alive, and fully mature was discovered after extraction. Some of the seeds were packed and stored in a $4{ }^{\circ} \mathrm{C}$ storage freezer (Ugur Cooling Inc., Co., Aydın, Turkey) and the other portion in room conditions $\left(20^{\circ} \mathrm{C}, 50 \%\right.$ relative humidity $\left.(\mathrm{RH})\right)$ after they were extracted from their seed capsules and cleaned. Measurements and counts were performed regarding the physiological and morphological features of the seeds.

\section{Germination tests}

The germination tests were conducted in a Lovibond TC $140 \mathrm{G}$ thermostatically controlled incubator (Liebherr, Dortmund, Germany). The glass Petri dished used were $100 \mathrm{~mm} \times 20 \mathrm{~mm}$. Before the treatments, the seeds were sterilized by washing three times with distilled water after they were steeped in ethanol $70 \%$ for $1 \mathrm{~min}$. They were then soaked in sodium hypochlorite solution $20 \%(5.25 \% \mathrm{NaOCl}$, Koruma Cleaning Co., Kocaeli, Turkey) for $10 \mathrm{~min}$. Petri dishes and blotting papers were used after they were sterilized at $100{ }^{\circ} \mathrm{C}$ for $30 \mathrm{~min}$. Distilled water was used for preparation of the solutions and in Petri dishes. Two layers of blotting paper were placed at the bottoms of the Petri dishes, and these papers were dampened with $3 \mathrm{~mL}$ of purified water. Petri dishes were put on lids and wrapped in stretch film, and the germination tests were performed under a $12 / 12$ light regime in the germination incubator with shelves set to $20 \pm 0.5^{\circ} \mathrm{C}$. To prevent infection development in Petri dishes, a commercial fungicide (Sumiriz-T $60 \mathrm{WP}$ ) (SumiAgro Corp., Istanbul, Turkey) containing the agent of $30 \%$ tolclofos-methyl $+30 \%$ thiram was applied. Tests were performed in a 30-day period, and germinated seeds were counted at routine intervals (every 2 days). Seeds emerging with 2 -mm radicles were considered to be germinated, counted, and removed from the Petri dish (Eser et al. 2005; ISTA 2013). The final germination percentage (FGP) was employed in germination research.

\section{Determining the impact of seed storage temperature on germination}

Because it was thought that the germination feature is lost if the seeds have been kept in room conditions $\left(20{ }^{\circ} \mathrm{C}, 50 \% \mathrm{RH}\right)$, the germination percentages of the seeds kept in room conditions $\left(20{ }^{\circ} \mathrm{C}, 50 \% \mathrm{RH}\right)$ and at $4{ }^{\circ} \mathrm{C}$ were sought through comparison experiments. To set up these experiments, the cleaned seeds were stored at $4{ }^{\circ} \mathrm{C}$ for 7 months, while some seeds were stored in room conditions for same time. The seeds collected 2019 and the experiment settings were established with seeds stored in two different conditions in April 2020.

\section{Determining the optimum germination temperature}

To find out the germination performances of seeds at different temperatures, germination experiments were performed at four different temperatures of 10, 15, 20, and $25{ }^{\circ} \mathrm{C}$ by fixing all the other conditions ( $12 \mathrm{~h}$ light/12 h dark and humidity $80 \%$ ). Once the temperatures of 15 and $20{ }^{\circ} \mathrm{C}$ were determined more suitable for germination with these 
first experiments, the other germination studies were conducted at $20{ }^{\circ} \mathrm{C}$. Experiments were set up with freshly harvested unstored seeds in August 2019.

\section{Impact of light regime (photoperiodic treatments) on seed germination}

Germination experiments were set up in environments of constant light, 16-h light/8-h dark, 12-h light/12-h dark, 8-h light/16-h dark, and constant dark to determine the photoperiodical reactions of $V$. yurtkuranianum seeds. The temperature was set to a fixed $20^{\circ} \mathrm{C}$ in the experiments. Fifteen hundred lumen daylight-glow light bulbs were used as the light source. Experiments were established in April 2020 with seeds collected in 2019 and stored at $4{ }^{\circ} \mathrm{C}$ for 7 months.

\section{Determining the impacts of ultrasonic wave and vacuum treatments on germination percentage and speed}

The impact of 60 and 120 min vacuum and ultrasonic treatments on the germination percentage was investigated based on the literature reporting that ultrasonic wave and vacuum treatments speed up water absorption by seeds (Miyoshi and Mii 1998; CusTódio et al. 2016; Katsalirou et al. 2019). The seeds placed in small paper bags were laid on the plastic platform and put in the ultrasonic tank (Bandelin Sonorex Digiplus, Typ DL 510 $\mathrm{H}$, Berlin, Germany). The seeds were exposed to $35 \mathrm{kHz}$ ultrasonic wave treatment for periods of 60 and $120 \mathrm{~min}$. During the implementation, the water temperature was set to a fixed $25 \pm 2{ }^{\circ} \mathrm{C}$. For vacuum treatment, the seeds in small cloth bags were laid on a platform and placed in the vacuum device (Binder, VD 23, Tuttlingen, Germany). They were held in the $27.3{ }^{\circ} \mathrm{C}$ vacuum device for periods of 60 and 120 min under $380 \mathrm{~mm} / \mathrm{Hg}$ vacuum. Seeds kept in the same conditions and unexposed to vacuum were used as the control. To determine the germination speed as well as the final germination percentage (FGP), the period (in days) of the germination for $50 \%$ of the total number of germinated seeds was calculated. Experiments were established on 15 November 2019 with seeds collected in 2019 and stored at $4{ }^{\circ} \mathrm{C}$ for 2.5 months.

Determining the impacts of the cold-wet stratification, GA3, ultrasonic wave, vacuum, and warm-water soak combinations on germination

To increase the rates of germination, combinations of the following experiments were performed: $30{ }^{\circ} \mathrm{C}$ warm-water soak for $48 \mathrm{~h}$ together with cold stratification; holding in 1000 ppm GA3 solution (Merck, Darmstadt, Germany) for $24 \mathrm{~h}$; and 60 and $120 \mathrm{~min}$ of ultrasonic wave and vacuum treatments. Seeds were stored in the $4{ }^{\circ} \mathrm{C}$ repository, and only wet stratification-applied seeds were used as the control (Hartman et al. 1990; Eser et al. 2005; Baskin and Baskin 2014). Wet-cold stratification was applied by storing the seeds placed in Petri dishes in small bags made from blotting paper in a $4{ }^{\circ} \mathrm{C}$ repository and kept in dark conditions for 12 weeks. Otherwise, the seeds were placed in damp perlite in these bags and stored in a $4{ }^{\circ} \mathrm{C}$ repository in dark conditions for 12 weeks. The $30{ }^{\circ} \mathrm{C}$ water soak treatment was implemented, placing the seeds in 300-cc lid jars topped with pure water and held in an incubator $\left(30{ }^{\circ} \mathrm{C}\right)$ for $48 \mathrm{~h}$.

The treatment of $\mathrm{GA}_{3}$ solution was implemented by adding $50 \mathrm{cc}$ GA3 solution to the seeds placed in jars and kept in room conditions $\left(20^{\circ} \mathrm{C}\right.$ ) for $24 \mathrm{~h}$ (Hartman et al. 1990; Eser et al. 2005; Genç 2005). The seeds, which were stored for 3 months at $4{ }^{\circ} \mathrm{C}$, were put into cold-wet folding on December 1 (2019). Folding was terminated on March 1 (2020) and then the seeds were put into an incubator for germination. 
Founding the ex situ conservation parcel

The seeds germinated and were removed from the Petri dishes and were planted in turf environments in vials. The seedlings developing with continuous liveliness in vials were planted in the ex situ conservation field in outdoor conditions once they grew 2 to 3 small leaves.

\section{Experimental design and data analyses}

The experiments were established based on the Randomized Block Experimental Design. Three replications and 100 seeds for each replication were used. The study was conducted in the Bursa Technical University Laboratories (Bursa, Turkey) in 2019 and 2020. For the evaluation of the data acquired in the study, IBM SPSS Statistics 20 software (IBM Corp., Armonk, NY, USA) package program was employed. A T-test for the storage temperature data and one-way analysis of variance for other data was employed, and the operations between which differences were found were compared with a comparison test. Arc-sin data transformation was applied to the $\%$ germination rates acquired by counting.

\section{RESULTS AND DISCUSSION}

\section{Ornamental plant potential, morphological, and physiological features of the plant}

Table 1 exhibits the observation and measurement results regarding the life biology, morphological features, and ornamental plant characteristics of the species $V$. yurtkuranianum occurring in a single location (Fig. 2). The observations revealed that flower blooming takes place in May, June, and July. The branching, even though limited, in the plant proves that the plant can grow multiple peduncles if the removal of buds is practiced.

The percentage of the flowering plants in the plant population was $23.1 \%$. The flowers start to bloom from the lower end of the peduncles, and new buds continue to grow at the top. Flowering continues at the top even if the first blooming flowers have gone to seed and have been capsulated. This feature ensures flower blooming for approximately 2 months and increases the aesthetic value of the plant. During the field work, the plant is picked and used as vase bouquets. Although it was discovered during the field observations that all the leaves were scorched and disappeared after July, the plant in the ex situ conservation garden founded in a culture medium preserved all its green parts and did not suffer from any damage at the below-zero temperatures with a minimum $-11^{\circ} \mathrm{C}$ for $20 \mathrm{~h}$ in the winter. 
Table 1. Data on Plant Development and Life Biology of $V$. yurtkuranianum

\begin{tabular}{|c|c|}
\hline Parameter & Time / Amount / Size \\
\hline Start date of flower blooming of the species & $\begin{array}{c}\text { The first week of April } \\
\text { Level areas the southern slopes the first } \\
\text { week of May; } \\
\text { of May }\end{array}$ \\
\hline The last flower-blooming time in the population & End of June \\
\hline Average number of leaves per plant (quantity) & 14.4 \\
\hline Leaf length (including the rachis) (cm) & 18 to 21 \\
\hline Leaf blade length (cm) & 13 \\
\hline Leaf width (cm) & 6 to 8 \\
\hline Peduncle length (including the ear) (cm) & 100.31 \\
\hline The length of the ear of flower (cm) & 55.65 \\
\hline The number of corollas per ear (quantity) & 63.79 \\
\hline Average branching per peduncle (quantity) & 1.09 \\
\hline
\end{tabular}
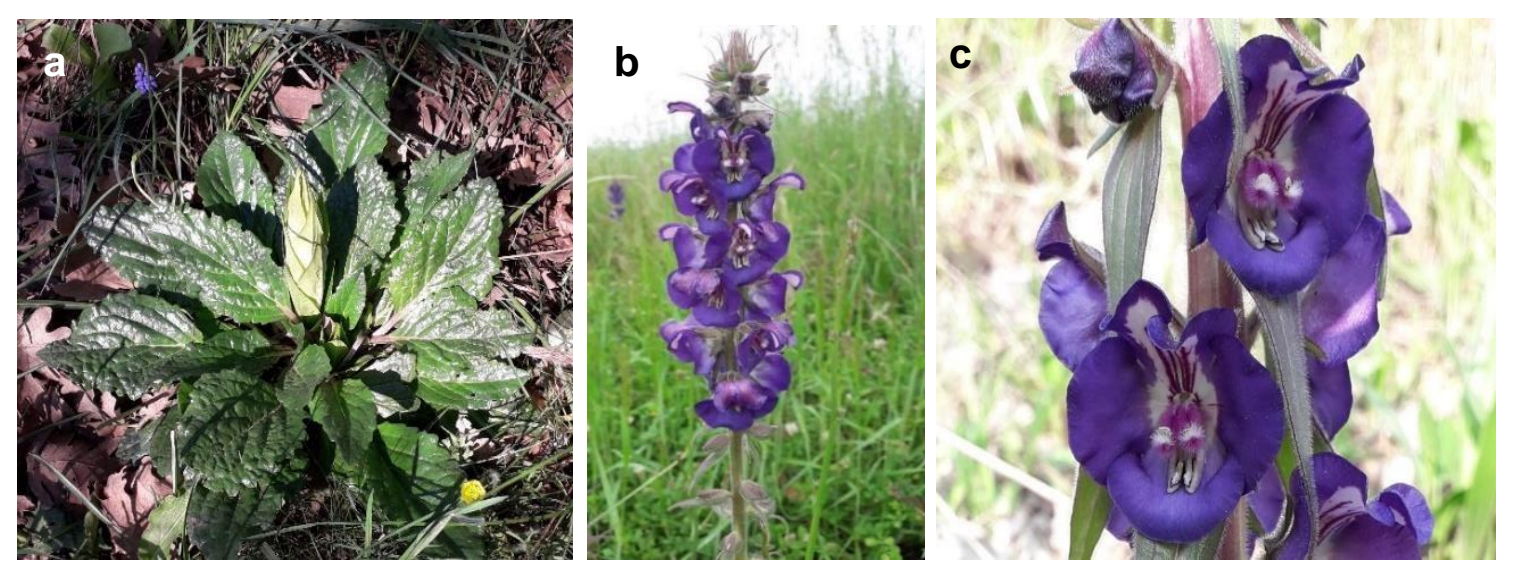

Fig. 2. General view of $V$. yurtkuranianum plants: a) rosette, b) inflorescence of plant, and c) flowers

The observations of $V$. yurtkuranianum revealed that the flower-bearing period of the population, one of the essential characteristics, is approximately 70 days. This period is quite a long time for single-peduncle Verbascum species. For example, in the study conducted on the multi-peduncle $V$. thapsus species by Ivanova and Valchev (2020), the flower-bearing period was determined as 72.1 to 91.4 days. V. yurtkuranianum represents a different leaf structure from other Verbascum species. Particularly, its hairless and bright green leaves increase the potential use of this species as an ornamental plant. Among the species of the genus Verbascum (Huber-Morath 1978), it is similar to the V. bugilifolium species in leaf structure and peduncles (Kaynak et al. 2006) and to the $V$. weidemannianum species with amaranth purple corolla in corolla structure (Senel et al. 2007), in spite of its difference in corolla color (blue). Unlike the $V$. wiedemannianum, it has hairless leaves and violet flowers, and it grows fewer pedicels per peduncle. Unlike the V. bugilifolium, the base color of $V$. yurtkuranianum corolla is blue. 


\section{Morphological features of the seed}

The seed pods that develop on the plant are observed to start growing ripe from mid-July and dehiscing towards the end of July. It is noteworthy that because the flower blooming of the plant continues for a long time, ripening of the pods (and therefore the seeds) extends over a long period; moreover, the seeds in some pods dry out before ripening due to extremely hot climatic conditions. Pods that have dehisced and ripened recently and have not ripened yet exist concurrently on a plant. The pods must be harvested at the lower parts to collect seeds for production. The data obtained regarding the physiological and morphological features of the seeds are demonstrated in Table 2 and Fig. 3.

Table 2. Physiological and Morphological Features of $V$. yurtkuranianum seeds

\begin{tabular}{|c|c|}
\hline Quality & Time / Amount / Unit \\
\hline Seed ripening time & Mid-July \\
\hline Seed throwing time & End of July \\
\hline Average number of seeds in a pod (quantity) & 136.96 \\
\hline Seed width $(\mathrm{mm})$ & 0.8 \\
\hline Seed length $(\mathrm{mm})$ & 1.2 \\
\hline Weight of 1000 seeds (g) & 0.1899 \\
\hline The number of seeds in $1 \mathrm{~g}$ (quantity) & 5265.9 \\
\hline
\end{tabular}
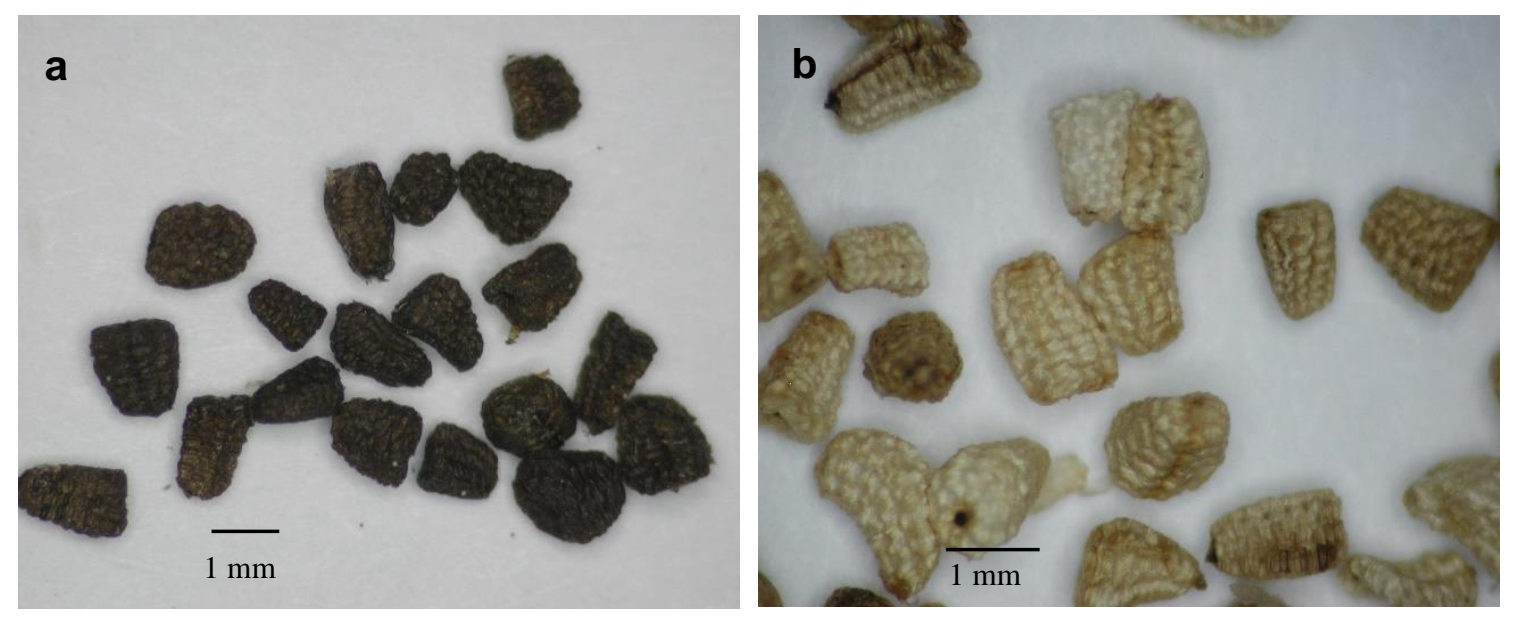

Fig. 3. Seeds of $V$. yurtkuranianum: a) natural seeds view and b) seeds view after sterilization (photos from a Irmeco stereomicroscope -Krüss Optronic, Hamburg, Germany)

\section{Seed storage temperature}

According to the results of the experiment's set up to determine the seed storage temperature, a higher and also statistically significant germination percentage was obtained from the seeds stored in $4{ }^{\circ} \mathrm{C}$ dry storage conditions (Table 3 ). Storing the seeds at $4{ }^{\circ} \mathrm{C}$ ensured germination of $25.7 \%$ more seeds. This expected result corresponds to the recommendations of Hong and Ellis (1996), De Vitis et al. (2020), and Palomeque et al. (2020) to store the seeds at a temperature between 0 and $5{ }^{\circ} \mathrm{C}$ for short-term storage (12 to 18 months). 
Table 3. Impact of Storage Temperature on Germination Percentage of $V$. yurtkuranianum Seeds

\begin{tabular}{|c|c|}
\hline Seed Storage Temperature & Mean Germination (\%) \pm SE \\
\hline Storing at room temperature $\left(20^{\circ} \mathrm{C}, 50 \% \mathrm{RH}\right)$ & $45.00 \pm 1.52 \mathrm{~b}^{*}$ \\
\hline Storing at $4{ }^{\circ} \mathrm{C}$ & $70.67 \pm 2.93 \mathrm{a}$ \\
\hline
\end{tabular}

*: Within each column, means with the same letter are not significantly different $(p \leq 0.019)$; SE: standard error

\section{Optimum germination temperature}

Different temperature treatments in the germination experiments conducted to determine the optimum germination temperature of the seeds were discovered to have a significant impact on seed germination (Table 4). No significant difference was observed at the temperatures of 15 to $20{ }^{\circ} \mathrm{C}$ for seed germination percentages. The $36.7 \%$ germination obtained in $10{ }^{\circ} \mathrm{C}$ germination environment revealed that this species can germinate in cool climates as well.

Table 4. Impact of Different Temperature Regimes on the Germination of $V$. yurtkuranianum Seeds

\begin{tabular}{|c|c|}
\hline Temperature $\left({ }^{\circ} \mathbf{C}\right)$ & Germination (\%) \pm SE \\
\hline 10 & $36.67 \pm 7.5 \mathrm{~b}^{*}$ \\
\hline 15 & $\mathbf{7 7 . 3 3} \pm \mathbf{0 . 5} \mathbf{a}$ \\
\hline 20 & $\mathbf{7 8 . 6 7 \pm 1 . 7 \mathbf { a }}$ \\
\hline 25 & $4.00 \pm 1.8 \mathrm{C}$ \\
\hline
\end{tabular}

*: Within each column, means with the same letter are not significantly different $(p=0.05)$; SE: standard error

According to the results acquired from the temperature experiments, the temperatures of $15{ }^{\circ} \mathrm{C}(77.3 \%)$ and $20^{\circ} \mathrm{C}(78.7 \%)$ are more suitable for the germination of $V$. yurtkuranianum seeds. Şenel et al. (2007) determined that for $V$. bithynicum and $V$. wiedemannianum species and Ganatsas et al. (2019) for V. dingleri species the optimum seed germination temperature was $20^{\circ} \mathrm{C}$, as in the current study. In the study conducted on germination of the $V$. dudleyanum, $V$. natolicum, $V$. serratifolium, and $V$. suworowianum var. suworowianum species, the results of Isı et al. (2017) reflected the highest germination at a temperature, $22{ }^{\circ} \mathrm{C}$, which is close to the results of the current study. In a study on nine taxa of Verbascum spp, Catara et al. (2016) produced good results in certain species at a $25^{\circ} \mathrm{C}$ temperature environment in addition to 15 and $20^{\circ} \mathrm{C}$. However, in the current study, the germination percentage obtained at $25{ }^{\circ} \mathrm{C}(4.0 \%)$ decreased considerably while high-level germinations were provided similarly at 15 and $20{ }^{\circ} \mathrm{C}$ (77.3\% and 78.7\%). Leite and Takaki (2001) concluded that germination temperatures can vary based on species. Accordingly, Sarıbayır (2001) found the germination temperatures for the species $V$. olympicum, $V$. bombyciferum, and $V$. prusianum as 4 to $7^{\circ} \mathrm{C}$, which is distinctively different from the results of the current study. Seipel et al. (2015) provided high germination percentages at a temperature range between 20 and $35^{\circ} \mathrm{C}$ in $V$. thapsus seeds collected from samples of different ecological conditions. In contrast, in the author's study, the germination percentage was reduced considerably at the temperature of $25^{\circ} \mathrm{C}$. 
Even though Catara et al. (2016) reported better results in alternating temperature treatments compared to fixed temperature, the high germination percentages in the current study were obtained with $20{ }^{\circ} \mathrm{C}$ fixed temperature treatments. There are studies revealing that germination-enhancing effects of hormones are more significant at fixed temperatures between 20 and $25{ }^{\circ} \mathrm{C}$ (Chen et al. 2008) and high temperatures lead to deceleration of germination (Núñez and Calvo 2000; Shen et al. 2010). Alba et al. (2016) concluded that genetic differences developed regarding germination in natural and cultural forms of the species $V$. thapsus, this difference is more significant in natural populations and, therefore, natural populations of a species can germinate at different temperature ranges.

Impacts of light regime (photoperiodic treatments) on seed germination

According to the results acquired from the experiments to determine the response of seeds to photoperiodism, the light conditions of the germination environment were discovered to have a statistically significant impact on seed germination (Table 5). While the implementation of constant dark completely inhibited germination, the photoperiodic treatments of 12 / 12 and 8 / 16 light / dark were detected to be effective light regimes for V. yurtkuranianum seed germination.

Table 5. Impact of Different Photoperiodic Treatments on V. yurtkuranianum Seed Germination

\begin{tabular}{|c|c|}
\hline Photoperiodic Treatments & Mean Germination (\%) \pm SE \\
\hline 24-h constant light & $18.67 \pm 1.58 \mathrm{c}$ \\
\hline 16-h light / 8-h dark & $64.00 \pm 1.81 \mathrm{~b}$ \\
\hline 12-h light / 12-h dark & $\mathbf{7 4 . 6 7 \pm 3 . 5 8 ~ a}$ \\
\hline 8-h light / 16-h dark & $\mathbf{7 6 . 0 0 \pm 2 . 0 2 ~ a}$ \\
\hline 24-h constant dark & $0.00 \pm 0.00 \mathrm{~d}$ \\
\hline
\end{tabular}

${ }^{\star}$ : Within each column, means with the same letter are not significantly different $(p=0.001)$; SE: standard error

Unlike the current study, Senel et al. (2007) found that to establish the seed germination protocols of $V$. bithynicum and $V$. wiedemannianum, a dark environment was the best treatment. Is1k et al. (2017) acquired the best germination results for the $V$. dudleyanum, $V$. natolicum, $V$. serratifolium, $V$. suworowianum, $V$. suworowianum, and $V$. orientale species by applying the 8-h light/16-h dark periodic regime. In agreement with the current study, they achieved the best germination rate for the $V$. wiedemannianum species with the 16-h light/8-h dark photoperiodic regime, which falls into the secondary group in the current study. Senel et al. (2007) found that the effect of treatments of light, dark, and photoperiod can vary based on the species, and they should be established separately and meticulously for each species. Chanyenga et al. (2012), in contrast, reported that seeds of certain species can equally germinate both in light and dark conditions.

Impact of ultrasonic wave and vacuum treatments on germination

According to the results obtained from the vacuum (V) and ultrasonic wave (UW) treatments, the germination statistics of $V$. yurtkuranianum seeds were affected significantly $(\mathrm{P}<0.05)$ and positively (Table 6$)$. The best results were achieved from 60 
min UW and 120 min V implementations. Because the 120 min UW implementation provided lower germination than the control implementation, it was determined that this period is too long for this treatment and affects germination negatively. Both 60 min UW and $120 \mathrm{~min} \mathrm{~V}$ implementation were observed to have a statistically same-level impact.

Table 6. Impact of Ultrasonic Wave and Vacuum Treatments on $V$. yurtkuranianum Seed Germination

\begin{tabular}{|c|c|c|}
\hline Treatment & Mean Germination (\%) \pm SE & Germination Speed ( $\mathbf{T}_{\mathbf{5 0}}$ ) (Day) \\
\hline Control & $85.33 \pm 2.8 \mathrm{bc}^{*}$ & 5.0 \\
\hline 60 min Ultrasonic Wave & $\mathbf{9 4 . 3 3} \pm \mathbf{2 . 0} \mathbf{a}$ & 5.0 \\
\hline 120 min Ultrasonic Wave & $83.33 \pm 0.7 \mathrm{c}$ & 5.0 \\
\hline 60 min Vacuum & $91.00 \pm 2.4 \mathrm{ab}$ & 5.3 \\
\hline 120 min Vacuum & $\mathbf{9 5 . 3 3} \pm 1.4 \mathrm{a}$ & 5.0 \\
\hline
\end{tabular}

*Within each column, means with the same letter are not significantly different $(p=0.05)$; SE: standard error

The 60 and 120 min V and 60 min UW implementations of UW and V treatments significantly increased germination percentages compared to the control. The fact that $\mathrm{V}$ treatments were more effective in implementation of both periods indicates that the $\mathrm{V}$ treatment had a wide impact. Implementing the UW doses for long periods affected germination negatively. A similar result was obtained in the study conducted by Mildažienè et al. (2019). The in vitro $200 \mathrm{~Pa}$ Vacuum (7 min) treatment in substrate for Helianthus annus seeds decreased the germination percentage compared to the control. In the study conducted on the impact of ultrasonic treatment time and temperature on sesame (Sesamun indicum) germination (Shekar1 et al. 2015), the 10 and 20 min implementations in optimal temperature conditions decreased germination in $20{ }^{\circ} \mathrm{C}$ germination environments while the $25{ }^{\circ} \mathrm{C}$ treatments increased germination $2 \%$ compared to the control. In the study conducted by López and Vicient (2017), while the ultrasonic treatment was observed to be ineffective on new Arabidopsis thaliana seeds, it was found to increase germination in old seeds. There are papers reporting an increase in the germination of certain species via ultrasonic wave implementation (Goussous et al. 2010; Machikowa et al. 2013; Sharififar et al. 2015; Liu et al. 2016). Contrary to this literature, there are also papers reporting a decrease in germination (Goussous et al. 2010; Fateh et al. 2012), as indicated by the results of 120 min ultrasonic wave treatment acquired in the current study.

\section{Germination speed of $V$. yurtkuranianum seeds}

To establish the germination speed of $V$. yurtkuranianum seeds, the germination speed in vacuum and ultrasonic wave treatments were also determined. In the $V$. yurtkuranianum seeds on which the treatments of control, vacuum, and ultrasonic wave were performed, the germination speed started on the $2^{\text {nd }}$ and $3^{\text {rd }}$ day and substantially finalized within 10 days. Particularly on the $4^{\text {th }}, 5^{\text {th }}$, and $6^{\text {th }}$ days, a dense germination occurred. The control finalized on the $14^{\text {th }}$ day in the $120 \mathrm{~min}$ UW and $60 \mathrm{~min}$ V treatments and $18^{\text {th }}$ day in the 60 min UW and 120 min V treatments (Fig. 4). 


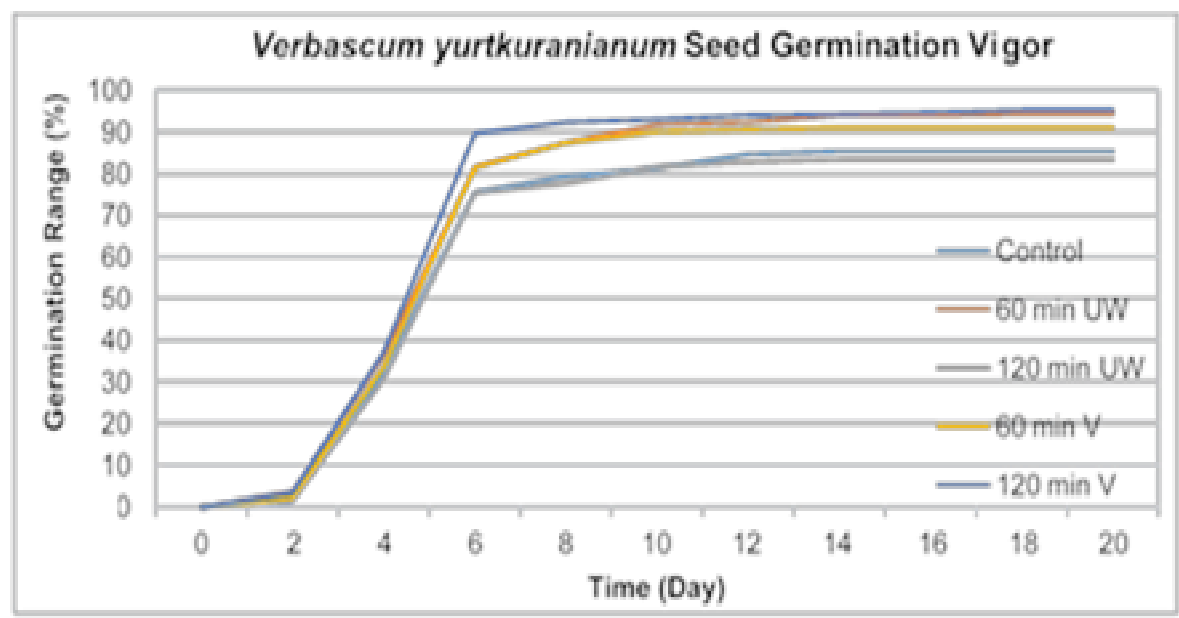

Fig. 4. The germination speed in the $V$. yurtkuranianum seeds on which ultrasonic wave and vacuum treatments were performed (seed germination trends)

It was observed in the experiments that germination was quite dense on the $3^{\text {rd }}, 4^{\text {th }}$, $5^{\text {th }}$, and $6^{\text {th }}$ day and substantially finalized between the $8^{\text {th }}$ and $10^{\text {th }}$ day, and the last germinations occurred on the $18^{\text {th }}$ day. The period for the highest germination energy in the $V$. thapsus species was the $5^{\text {th }}$ day by Ivanova and Valchev (2020), and the germination period for the V. calycosum species was established as 10.3 days by Hilooğlu et al. (2018). Hilooğlu and Sözen (2017) reported the germination speed index in the $V$. alyssifolium species as between 8.3 and 14.7 days, and the $T_{50}$ germination index as $6.2,7.5,7.0$, and 8.0 days in different treatments. This course took between 5.0 and 5.3 days in the current study. This difference between studies is presumed to be caused by the heterogeneity in the seeds obtained.

Impact of cold-wet stratification and GA3, ultrasonic wave, vacuum, and warm water soak combinations on germination

The impacts of the 3-month cold-wet stratification treatments in Petri dishes and a perlite environment and the combinations of these with different treatments on $V$. yurtkuranianum seed germination varied. Lower germination percentages were acquired from all the wet stratification treatments in Petri dishes compared to the control. In contrast, higher germination percentages were achieved from the cold stratification treatment in a wet perlite environment (Table 7). Similar to the nonstratified temperature experiments, results of the statistically same group were obtained in the stratified seeds in 15 and $20^{\circ} \mathrm{C}$ germination environments. The perlite used in the stratification environment was anticipated to promote the effect of stratification as it ensures a balanced humidity level. 
Table 7. Impacts of Cold-wet Stratification in Petri Dishes and Perlite and their Combinations with Other Treatments on V. yurtkuranianum Seed Germination

\begin{tabular}{|c|c|}
\hline Treatments & Germination (\%) \pm SE \\
\hline Control & $71.00 \pm 3.0 b^{*}$ \\
\hline 3-month cold-wet $\left(4^{\circ} \mathrm{C}\right)$ stratification in Petri dishes & $25.67 \pm 1.2 c$ \\
\hline $\begin{array}{l}\text { 3-month cold-wet }\left(4^{\circ} \mathrm{C}\right) \text { stratification in Petri dishes + 48-h soak in warm } \\
\text { water }\left(30^{\circ} \mathrm{C}\right)\end{array}$ & $3.67 \pm 2.5 d$ \\
\hline $\begin{array}{l}\text { 3-month cold-wet }\left(4^{\circ} \mathrm{C}\right) \text { stratification in Petri dishes }+24-\mathrm{h} \text { soak in } 1000 \\
\mathrm{ppm} \mathrm{GA}_{3}\end{array}$ & $0.33 \pm 1.9 \mathrm{de}$ \\
\hline $\begin{array}{c}\text { 3-month cold-wet }\left(4^{\circ} \mathrm{C}\right) \text { stratification in Petri dishes + 1-h ultrasonic } \\
\text { wave treatment }\end{array}$ & $24.33 \pm 1.9 c$ \\
\hline $\begin{array}{c}\text { 3-month cold-wet }\left(4^{\circ} \mathrm{C}\right) \text { stratification in Petri dishes + 2-h ultrasonic } \\
\text { wave treatment }\end{array}$ & $0.00 \pm 0.0 \mathrm{e}$ \\
\hline 3-month cold-wet $\left(4^{\circ} \mathrm{C}\right)$ stratification in perlite + germination at $15^{\circ} \mathrm{C}$ & $90.67 \pm 5.4 a$ \\
\hline 3-month cold-wet $\left(4^{\circ} \mathrm{C}\right)$ stratification in perlite + germination at $20^{\circ} \mathrm{C}$ & $91.67 \pm 4.8 \mathrm{a}$ \\
\hline
\end{tabular}

${ }^{*}$ : Within each column, means with the same letter are not significantly different $(p=0.05)$

The best and statistically most significant level results acquired from the experiments of stratification treatments and their combination of different treatments were achieved in the 3-month cold-wet stratification in perlite. In the study conducted on the 6 taxa of Verbascum- V. dudleyanum, V. anatolicum, V. serratifolium, V. wiedemannianum, and V. suworowianum var. suworowianum, Işik et al. (2017) achieved the highest germination percentage in the treatments combined with a 10-day cold-wet pre-treatment. The highest germination rate in $V$. orientale was attained from the treatments combined with a 48-h cold-wet pretreatment. Even though the cold-wet stratifications stand out, as in the current study, the treatment periods seem different.

Hilooğlu et al. (2018) obtained a germination of $23.2 \%$ in $V$. calycosum seeds from the 7-day cold stratification treatment at $4{ }^{\circ} \mathrm{C}$. Similarly, in the current study, a germination of $25.7 \%$ was obtained from the 3-month cold-wet stratification treatment in Petri dishes at the same temperature. These results present a value below the germination of the control implementation in the current study. In other words, cold stratification in Petri dishes affected germination negatively in the current study. Similar to these results, cold stratification treatments were reported to affect germination in the $V$. nigrum, $V$. speciosum, and $V$. thapsus species by Leo (2013) and the $V$. alyssifolium species by Hilooğlu and Sözen (2017). The germination rate reached $90.7 \%$ at $15{ }^{\circ} \mathrm{C}$ and $91.7 \%$ at 20 ${ }^{\circ} \mathrm{C}$ by applying stratification for 3 months in wet perlite.

Hilooğlu and Sözen (2017) achieved the best germination in the species V. alyssifolium with a mechanical stratification treatment. In another study, Hilooğlu et al. (2018) acquired germination percentages between $34.5 \%$ and $54.5 \%$ in $V$. calycosum seeds from mechanical abrasion treatment. Both of the studies reported that as the mechanical stratification treatments promoted germination, V. alyssifolium and V. calycosum seeds had physical dormancy due to their impermeable coats as well as to their physiological dormancy. However, in this study, a higher germination (91.7\%) was achieved by extending the period of cold stratification without any process for eliminating the physical 
dormancy. Attaining a germination in the $90^{\text {th }}$ percentile with only cold stratification treatment revealed, according to Baskin and Baskin (2014) and Wang et al. (2017), V. yurtkuranianum seeds have only physiological dormancy. Yang et al. (2020) reported elimination of physiological dormancy solely by cold stratification. This statement supports the findings of the current study.

Some of the study's worst results were obtained as $0.33 \%$ germination from the 24 $\mathrm{h}$ soak in the $1000 \mathrm{ppm} \mathrm{GA} 3$ solution in addition to the cold-wet stratification treatment. Similar results were obtained by Şenel et al. (2007) in the V. bithynicum and V. wiedemannianum species. In contrast to the current study and Senel et al. (2007), Hilooğlu and Sözen (2017) concluded that there was an increase in germination percentages by significant numbers with $\mathrm{GA}_{3}$ treatments in the species $V$. alyssifolium in comparison to the control.

Ganatsas et al. (2019) reported 32.0\%, 26.7\%, and 40.0\% germinations from seeds of different sizes in the species $V$. dingleri without any treatments. In the current study, $85.3 \%$ and $71.0 \%$ germinations were obtained in the controls of both experiments in which no treatment was executed. These results constitute an advantage for the production and ex situ conservation works of the species $V$. yurtkuranianum.

Germination results were widely varied based on species and can be represented in germination studies conducted under the same conditions in different Verbascum species. While germination rates in the 0 to 1 percentile can be obtained by implementing all the treatments in certain species, a $96 \%$ germination rate can be achieved in certain species with the same treatments. These results reveal that the species of the genus Verbascum are affected in quite different ways from the treatments of light, temperature, photoperiod, and various dormancy elimination based on the species (Isik et al. 2017). Another reason to obtain different results in similar studies can be the germination-affecting storage process conditions in the waiting period between the harvesting and germination stages (Probert 2000). Considerable differences can arise regarding the germination characteristics of plant species based on genetic and environmental factors and even the environments utilized for germination testing (Elias et al. 2012; Baskin and Baskin 2014). It was recorded by some researchers that seed germination percentages can be affected even by the side of the plant bearing the fruit from which the seed was collected (Nielsen 1988; Copeland and McDonald 2001). Consequently, germination is a remarkably complex physiological process and can be affected by a wide range of factors (Gresta et al. 2010).

\section{Ex situ conservation parcel}

788 individuals of the locally endemic V. Yurtkuranianum species were counted in the wild. Its natural habitat is at great risk as it is close to the settlement. Therefore, ex situ conservation is required to protect the species. V. yurtkuranianum ex situ conservation parcel was established with the seedlings germinated during the experiments and developed in vials (Fig. 5). This parcel ensured protection of this endangered narrow endemic species as well as its natural distribution locality. The research related to this species will persevere in this parcel, and the plants and seeds from this parcel will be utilized for further studies. Thus, collecting seeds from the natural populations of this species will not be necessary at the next stage, even for scientific purposes. The studies to be conducted in this parcel will ensure cultivation of this species and its use as an ornamental plant. 

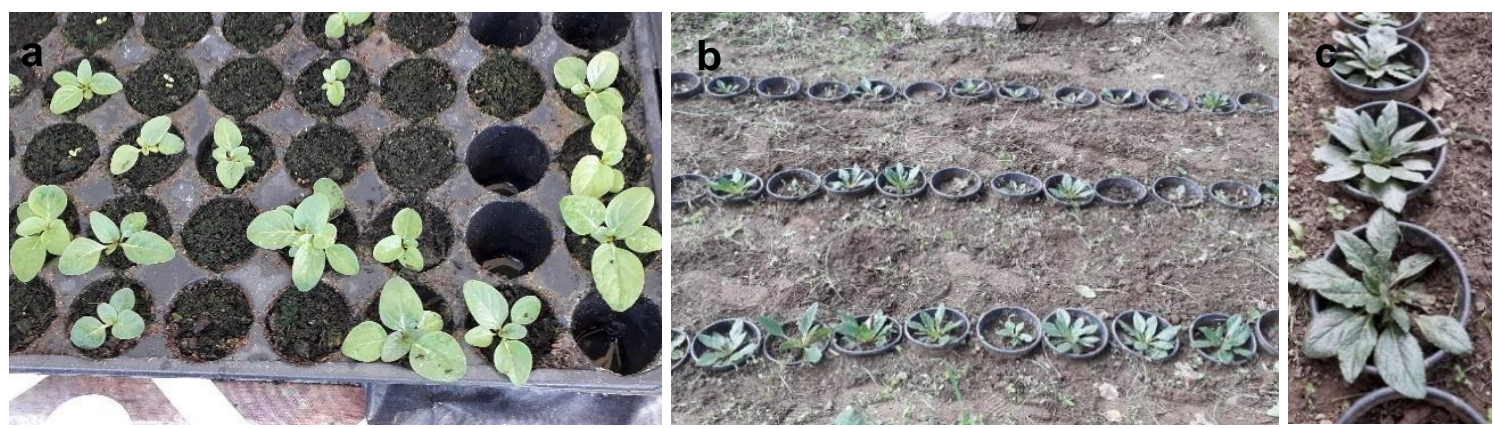

Fig. 5. Producing $V$. yurtkuranianum seedlings and the status of the plants planted in the ex situ conservation area; a) seedlings view grown in viols, b) seedlings view planted in the garden, and c) close view of plants

\section{CONCLUSIONS}

Verbascum yurtkuranianum has high ornamental plant potential with its flower color, flower life and the number of flowers per plant.

Germination rates of $94.3 \%$ were obtained from 60 min ultrasonic wave and $95.3 \%$ from 120 min vacuum treatment. In addition, an acceptable level of germination $(91.7 \%)$ was achieved treatment of 3 months cold-wet $\left(4{ }^{\circ} \mathrm{C}\right)$ stratification in the perlite which does not require a technical equipment.

An ex situ conservation garden was established with the plants obtained during the study for this species, which only 788 individuals remained in the natural habitat. Future studies will continue with seeds obtained from this garden and no material will be collected from natural population.

The results revealed that generative production and ex-situ conservation are feasible for the $V$. yurtkuranianum species. The high germination rates obtained for this species is sufficient for fast production in the culture conditions.

\section{ACKNOWLEDGMENTS}

Special thanks to the Unit of Scientific Research Projects of Bursa Technical University (Bursa, Turkey) for their financial support (Project number: 191N013). We would like to thank the staff of the Republic of Turkey Ministry of Agriculture and Forestry, the $2^{\text {nd }}$ Regional Directorate of Nature, Conservation and National Parks for their support in the fieldwork. 


\section{REFERENCES CITED}

Alba, C., Moravcová, L., and Pyšek, P. (2016). “Geographic structuring and transgenerational maternal effects shape germination in native, but not in introduced, populations of a widespread plant invader," American Journal of Botany 103(5), 837844. DOI: $10.3732 / \mathrm{ajb} .1600099$

Alp, Ş., Zeybekoğlu, E., Salman, A., and Özzambak E. (2020). "Cultivation process of natural plants and their use as ornamental plants," Journal of Agricultural Faculty of Bursa Uludag University 34 (special issue), 351-357.

Bacchetta, G., Fenu, G., Mattana, E., Piotto, B., and Virevaire, M. (2006). Manuale Per La Raccolta, Studio, Conservazione E Gestione Ex Situ Del Germoplasma [Manual for the Collection, Study, Preservation and Management of Ex Situ Germplasm], Italian Agency for Environmental Protection and Technical Services (APAT), Rome, Italy, pp. 248.

Baskin, C. C., and Baskin, J. M. (2014). Seeds: Ecology, Biogeography, and Evolution of Dormancy and Germination (2nd ed.), Elsevier/Academic Press, San Diego, CA, USA.

Brzuszek, R. F., Harkess, R. L., and Kelly, L. (2010). "Survey of master gardener use of native plants in the Southeastern United States," HortTechnlogy 20(2), 462-466.

DOI: 10.21273/HORTTECH.20.2.462

Catara, S., Cristaudo, A., Gualtieri, A., Galesi, R., Impelluso, C., and Onofri, A. (2016). "Threshold temperatures for seed germination in nine species of Verbascum (Scrophulariaceae)," Seed Science Research 26(1), 30-46. DOI: $10.1017 / \mathrm{S} 0960258515000343$

Cenil, T. (2007). Morphologic and Taxonomic Research on the Verbascum sp. of Bursa Province, Master's Thesis, Bursa Uludag University, Bursa, Turkey.

Cesur, C., Coşge Senkal, B., Uskutoğlu, T., Yaman, C., and Yurteri, T. (2017). "A study on the determination of optimum germination methods for cocklebur seeds (Xanthium strumarium L.)," Turkish Journal of Agricultural Research 4(2), 124-130. DOI: $10.19159 /$ tutad.270676

Chanyenga, T. F., Geldenhuys, C. J., and Sileshi, G. W. (2012). "Germination response and viability of an endangered tropical conifer Widdringtonia whytei seeds to temperature and light," South African Journal of Botany 81, 25-28. DOI: 10.1016/j.sajb.2012.04.002

Chen, S., Kuo, S., and Chien, C. (2008). "Roles of gibberellins and abscisic acid in dormancy and germination of red bayberry (Myrica rubra) seeds," Tree Physiology 28(9), 1431-1439. DOI: 10.1093/treephys/28.9.1431

Copeland, L. O., and McDonald, M. B. (2001). Principles of Seed Science and Technology $\left(4^{\text {th }} \mathrm{Ed}\right)$, Springer Science + Business Media, New York, NY, USA.

Custódio, C. C., Marks, T. R., Pritchard, T. W., Hosomi, S., and Machado-Neto, N. B. (2016). "Improved tetrazolium viability testing in orchid seeds with a thick carapace (Dactylorhiza fuchsii) or dark seed coat (Vanda curvifolia)," Seed Science and Technology 44(1), 177-188. DOI: 10.15258/sst.2016.44.1.17

De Vitis, M., Hay, F. R., Dickie, J. B., Trivedi, C., Choi, J., and Fiegener, R. (2020). "Seed storage: Maintaining seed viability and vigor for restoration use," Restoration Ecology 28(S3), 249-255. DOI: 10.1111/rec.13174 
Elias, S. G., Copeland, L. O., McDonald, M. B., and Baalbaki, R. Z. (2012). Seed Testing-Principles and Practices, Michigan State University Press, East Lansing, MI, USA.

El-Dengawy, E. F. A. (2005). "Promotion of seed germination and subsequent seedling growth of loquat (Eriobotrya japonica, Lindl) by moist-chilling and GA3 applications," Scientia Horticulturae 105(3), 331-342. DOI: 10.1016/j.scienta.2005.01.027.

Erdoğan, E., Kaynak, G., Daşkın, R., and Yılmaz, O. (2011). "The vascular flora of Katırlı mountain (Bursa/Turkey)," Biological Diversity and Conservation 4(1), 159-181.

Erken, K., Özzambak M. E., and Zencirkıran M. (2021). Cultivation Processes of Natural Plants from Forest to Garden, İn; Current Studies in Landscape Architecture (Planning, Design and Landscape Plants) (Editor; Murat Zencirkıran) Gece Library, 1st Edition, ISBN; 978-625-7462-55-6, Chapter 2, pp. 19-52. Ankara

Eser, B., Saygılı, H., Gökçöl, A., and İlker, E. (2005). Seed Science and Technology (Publication No. 3), (Vol.I-II), Ege University Seed Technology Application and Research Center, Izmir, Turkey.

Fateh, E., Noroozi, H., Farbod, M., and Gerami, F. (2012). "Assessment of fennel (Foeniculum vulgare) seed germination characteristics as influenced by ultrasonic waves and magnetic water," Eur. Journal of Experimental Biology 2(3), 662-666.

Ganatsas, P., Tsakaldimi, M., Damianidis, C., Stefanaki, A., Kalapothareas, T., Karydopoulos, T., and Papapavlou, K. (2019). "Regeneration ecology of the rare plant species V. dingleri: Implications for species conservation," Sustainability 11(12), article no. 3305. DOI: 10.3390/su11123305

García, F. M., García, S. G., and Pérez-García, F. (2012). "Evaluation of reproductive success and conservation strategies for Senecio coincyi (Asteraceae), a narrow and threatened species," Australian Journal of Botany 60(6), 517-525. DOI: 10.1071/BT12109

Genç, M. (2005). Ornamental Plants Growing (Volume 1, Publication No: 55), Süleyman Demirel University Faculty of Forestry, Isparta, Turkey.

Goussous, S. J., Samarah, N. H., Alqudah, A. M., and Othman, M. O. (2010). "Enhancing seed germination of four crops species using an ultrasonic technique," Experimental Agriculture 46(2), 231-242. DOI: 10.1017/S0014479709991062

Gresta, F., Cristaudo, A., Onofri, A., Restuccia, A., and Avola, G. (2010). "Germination response of four pasture species to temperature, light, and post-harvest period," Plant Biosystems 144(4), 849-856. DOI: 10.1080/11263504.2010.523549

Hartman, T. H., Kester, E. D., and Davies, T. F. (1990). Plant Propagation Principles and Practices ( $5^{\text {th }}$ Ed.), Prentice Hall Inc., Englewood Cliffs, NJ, USA.

Henting, W. (1998). "Strategies of evaluation and introduction of new ornamental plants," Acta Horticulturae 454, 65-80. DOI: 10.17660/ActaHortic.1998.454.6

Hilooğlu, M., and Sözen, E. (2017). "In vitro seed germination study in narrow endemic plant Verbascum alyssifolium (Scrophulariaceae)," Fresenius Environmental Bulletin 26(7), 4692-4696.

Hilooğlu, M., Sözen, E., Yücel, E., and Kandemir, A. (2018). "Chemical applications, scarification and stratification effects on seed germination of rare endemic Verbascum calycosum Hausskn. ex Murb. (Scrophulariaceae)," Notulae Botanicae Horti Agrobotanici Cluj-Napoca 46(2), 376-380. DOI: 10.15835/nbha46210746 
Hong, T. D., and Ellis, R. H. (1996). "A protocol to determine seed storage behaviour," in: IPGRI Technical Bulletin No. 1, J. M. M. Engels and J. Toll (Eds.), International Plant Genetic Resources Institute, Rome, Italy, pp. 1-62. DOI: 10.14712/23361964.2019.6

Huber-Morath, A. (1978). "Verbascum L.," in: Flora of Turkey and the East Aegean Islands (Supp 6), P.H. Davis, (Ed.), Edinburgh University Press, Edinburgh, United Kingdom, pp. 461-603.

Isik, G., Karaveliogullari, F. A., Yucel, E., and Celik, S. (2017). "Seed germination responses of some Verbascum L. species to different cold-wet pre-treatments and photoperiod processes," Bangladesh Journal of Botany 46(3), 939-946.

ISTA (International Seed Testing Association) (2013). "International rules for seed testing," ISTA, Bassedorf, Switzerland.

Ivanova, V., and Valchev, N. (2020). "Study of the influence of different sowing periods on the phenological and decorative characteristics of Verbascum thapsus L.," Scientific Papers. Series B: Horticulture 64(1), 584-587

Jones, C. D., Stevens, M. R., Jolley, V. D., Hopkins, B. G., Jensen, S. L., Turner, D., and Stettler, J. M. (2016). "Evaluation of thermal, chemical, and mechanical seed scarification methods for 4 Great Basin lupine species," Native Plants Journal 17(1), 5-17. DOI: 10.3368/npj.17.1.5

Katsalirou, E., Gerakis, A., and Haldas, X. (2019). “Optimal scarification times for seeds of two Mediterranean orchids," European Journal of Environmental Sciences 9(1), 47-52. DOI: 10.14712/23361964.2019.6

Kaynak, G., Daşkın, R., Yilmaz, O., and Erdoğan, E. (2006). "Verbascum ex (Scrophulariaceae), a new species from northwest Anatolia, Turkey," Annales Botanici Fennici 43(6), 456-459.

Kırmızı, S., Arslan, H., and Güleryüz, G. (2019). "The effects of cold stratıfication treatments on the germination of endemic Muscari bourgaei seeds," in: Proceedings of the I. International Ornamental Plants Congress, M. Zencirkiran (ed.), Bursa Uludag University, Bursa, Turkey, pp. 46-50.

Leite, I. T. A., and Takaki, M. (2001). "Phytochrome and temperature control of seed germination in Muntingia calabura L. (Elaeocarpaceae)," Brazilian Archives of Biology and Technology 44(3), 297-302. DOI: 10.1590/S1516-89132001000300012

Leo, J. (2013). The Effect of Cold Stratification on Germination in 28 Cultural Relict Plant Species, Master's Thesis, Swedish University of Agricultural Sciences, Ultuna, Sweden.

Liu, J., Wang, Q., Karagić, Đ., Liu, X., Cui, J., Gui, J., Gu, M., and Gao, W. (2016). "Effects of ultrasonication on increased germination and improved seedling growth of aged grass seeds of tall fescue and Russian wildrye," Scientific Reports 6, article no. 22403 DOI: 10.1038/srep22403

Locke, H., Ellis, E. C., Venter, O., Schuster, R., Ma, K., Shen, X., Woodley, S., Kingston, N., Bhola, N., Strassburg, B. B. N., et al. (2019). "Three global conditions for biodiversity conservation and sustainable use: An implementation framework," National Science Review 6(6), 1080-1082. DOI: 10.1093/nsr/nwz136

López, I., and Vicient, C. M. (2017). "Use of ultrasonication to increase germination rates of Arabidopsis seeds," Plant Methods 13(1), article no. 31. DOI: 10.1186/s13007017-0182-6 
Luo, M. R. (2016). Handbook of Ultrasonics and Sonochemistry, Springer Science + Business Media, Gateway East, Singapore. DOI: 10.1007/978-981-287-278-4

Machikowa, T., Kulrattanarak, T., and Wonprasaid, S. (2013). "Effects of ultrasonic treatment on germination of synthetic sunflower seeds," International Journal of Biological, Biomolecular, Agricultural Food Biotechnological Engineering 7(1), 13.

Mikkelsen, J. C. (1987). "Commercial aspects of new crop development," Acta Horticulturae 205, 49-55. DOI: 10.17660/ActaHortic.1987.205.8

Mildažienè, V., Aleknavičiūtè, V., Žūkienė, R., Paužaitė, G., Naučienė, Z., Filatova, I., Lyushkevich, V., Haimi, P., Tamošiūnè, I., and Baniulis, D. (2019). "Treatment of common sunflower (Helianthus annus L.) seeds with radio-frequency electromagnetic field and cold plasma induces changes in seed phytohormone balance, seedling development and leaf protein expression," Scientific Reports 9(1), article ID 6437. DOI: 10.1038/s41598-019-42893-5

Miyoshi, K., and Mii, M. (1998). "Stimulatory effects of sodium and calcium hypochlorite, pre-chilling and cytokinins on the germination of Cypripedium 706 macranthos seed in vitro," Physiologia Plantarum 102(4), 481-486. DOI: 10.1034/j.1399-3054.1998.1020401.x

Nazari, M., and Eteghadipour, M. (2017). "Impacts of ultrasonic waves on seeds: A mini709 review," Agricultural Research \& Technology 6(3), article ID 555688. DOI: 710 10.19080/ARTOAJ.2017.06.555688

Nielsen, K. K. (1988). "Dormancy in seeds from different positions on individual plants," 712 Acta Horticulturae 226, article no. 30. DOI: 10.17660/Acta Hortic.1988.226.30 713

Núñez, M. R., and Calvo, L. (2000). "Effect of high temperatures on seed germination of Pinus sylvestris and Pinus halepensis," Forest Ecology and Management 131(1-3). DOI:10.1016/S0378-1127(99)00211

Ocak, A., Öztürk, D., and Kara, I. (2017). Bilecik Florası (Flora of Bilecik), Bilecik Şeyh Edebali University Publications, Bilecik, Turkey

Öztürk, A., and Yiğit, N. (2013). "Some endemic in Turkey and possibilities of usage as ornamental plants," in: Proceedings of the V. Ornamental Plants Congress 2013, Yalova, Turkey, pp. 748-753.

Palomeque, X., Patiño, C., Marín, F., Palacios, M. A., and Stimm, B. (2020). "Effects of storage on seed germination and viability for three native tree species of Ecuador," Trees 34(17), 1487-1497. DOI: 10.1007/s00468-020-02018-2

Peng, D., Hu, X., Yang, J., and Sun, H. (2017). "Seed dormancy, germination and soil seed bank of Lamiophlomis rotata and Marmoritis complanatum (Labiatae), two endemic species from Himalaya-Hengduan Mountains," Plant Biosystems 152(4), 642-648. DOI: 10.1080/11263504.2017.1311959

Pollock, M., and Biante, J. (1996). "Always on trial," Garden-London 121(7), 428-431.

Probert, R. J. (2000). "The role of temperature in the regulation of seed dormancy and germination," in: Seeds: The Ecology of Regeneration in Plant Communities $\left(2^{\text {nd }}\right.$ Ed.), M. Fenner, (ed.), CAB International, Wallingford, CT, USA, pp. 261-292. DOI: $10.1079 / 9780851994321.0261$

Sarıbayır, B. (2001). Research on Seed Germination Physiology of Verbascum L. Species Endemic to Uludag, Master's Thesis, Bursa Uludag University, Bursa, Turkey. 
Schnadelbach, A., Barbosa, L. V., Ruiz, C., Pita, J. M., and Pérez-García, F. (2016). "Dormancy breaking and germination of Adenocarpus desertorum, Astragalus gines-lopezii and Hippocrepis grosii (Fabaceae) seeds, three threatened endemic Spanish species," Seed Science and Technology 44(1), 1-14. DOI: 10.15258/sst.2016.44.1.04

Seipel, T., Alexander, J. M., Daehler, C. C., Rew, L. J., Edwards, P. J., Dar, P. A., McDougall, K., Naylor, B., Parks, C., Pollnac, F. W., et al. (2015). "Performance of the herb Verbascum thapsus along environmental gradients in its native and nonnative ranges," Journal of Biogeography 42(1), 132-143. DOI: 10.1111/jbi.12403

Senel, E., Ozdener, Y., and Incedere, D. (2007). "Effect of temperature, light, seed weight and $\mathrm{GA}_{3}$ on the germination of Verbascum bithynicum, Verbascum wiedemannianum and Salvia dicroantha," Pakistan Journal of Biological Sciences 10(7), 1118-1121. DOI: 10.3923/pjbs.2007.1118.1121

Sharififar, A., Nazari, M., and Asghari, H. R. (2015). "Effect of ultrasonic waves on seed germination of Atriplex lentiformis, Cuminum cyminum, and Zygophyllum eurypterum," Journal of Applied Research on Medicinal and Aromatic Plants 2(3), 102-104. DOI: 10.1016/j.jarmap.2015.05.003

Shekari, F., Mustafavi, S. H., and Abbasi, A. (2015). "Sonication of seeds increase germination performance of sesame under low temperature stress," Acta Agriculturae Slovenica 105(2), 203-212. DOI: 10.14720/aas.2015.105.2.03

Shen, S., Wang, Y., and Ma, H. (2010). "Seed germination requirements and responses to desiccation and storage of Apterosperma oblata (Theaceae), an endangered tree from south-eastern China: Implications for restoration," Plant Species Biology 25(2), 158163. DOI: 10.1111/j.1442-1984.2010.00278.x

Wang, J., Baskin, J. M., Baskin, C., Liu, G., Yang, X., and Huang, Z. (2017). "Seed dormancy and germination of the medicinal holoparasitic plant Cistanche deserticola from the cold desert of northwest China," Plant Physiology and Biochemistry 115, 279-285. DOI:10.1016/j.plaphy.2017.04.010

Wong, K. S., Lee, L., Yeo, L. Y., and Tan, M. K. (2019). "Enhancing rate of water absorption in seeds via a miniature surface acoustic wave device," Royal Society Open Science 6(3), article ID 181560. DOI: 10.1098/rsos.181560

Yang, L., Peng, D., Li, Z. M., Huang, L., Yang, J., and Sun, H. (2020). “Cold stratification, temperature, light, $\mathrm{GA}_{3}$, and $\mathrm{KNO}_{3}$ effects on seed germination of Primula beesiana from Yunnan, China," Plant Diversity 42(3), 168-173. DOI: 10.1016/j.pld.2020.01.003

Article submitted: May 12, 2021; Peer review completed: August 21, 2021; Revised version received: September 7, 2021; Accepted: September 21, 2021; Published: September 24, 2021.

DOI: $10.15376 /$ biores.16.4.7530-7549 